\title{
Therapeutic effect of dual CAR-T targeting PDL1 and MUC16 antigens on ovarian cancer cells in mice
}

Tong Li and Jiandong Wang*

\begin{abstract}
Background: More favorable treatment against epithelial ovarian cancer (EOC) is urgently needed because of its insidious nature at an early stage and a low rate of five-year survival. The current primary treatment, extensive surgery combined with chemotherapy, exhibits limited benefits for improving prognosis. Chimeric antigen receptor $\mathrm{T}$ (CAR-T) cell technology as novel immunotherapy has made breakthrough progress in the treatment of hematologic malignancies, and there were also benefits shown in a partial solid tumor in previous research. Therefore, CAR-T cell technology may be a promising candidate as an immunotherapeutic tool against EOC. However, there are some weaknesses in targeting one antigen from the previous preclinical assay, such as ontarget off-tumor cytotoxicity. The dual-target CAR-T cell may be a better choice.

Methods: We constructed tandem PD1-antiMUC16 dual-CAR, PD1 single-CAR, and anti-MUC16 single-CAR fragments by PCR and genetic engineering, followed by preparing CAR-T cells via lentiviral infection. The expression of CAR molecules on single and dual CAR-T cells was detected by flow cytometry. The killing capacity and activation of CAR-T cells were measured by cytotoxic assays and cytokines release assays in vitro. The therapeutic capacity of CAR-T cells was assessed by tumor-bearing mice model assay in vivo.

Results: We successfully constructed CARs lentiviral expression vectors and obtained single and dual CAR-T cells. CAR-T cells demonstrated robust killing capacity against OVCAR-3 cells in vitro. Meanwhile, CAR-T cells released plenty of cytokines such as interleukin-2(IL-2), interferon- $\gamma$ (IFN- $\gamma$ ) and tumor necrosis factor-a(TNF-a). CAR-T cells showed a therapeutic benefit against OVCAR-3 tumor-bearing mice and significantly prolonged the survival time. Dual CAR-T cells were shown to be two to four times more efficacious than single CAR-T cells in terms of survival time.

Conclusion: Although exhibiting a similar ability as single CAR-T cells against OVCAR-3 cells in vitro, dual CAR-T cells demonstrated enhanced killing capacity against OVCAR-3 cells as compared to single CAR-T cells in vivo and significantly prolonged the survival time of tumor-bearing mice. PD1-antiMUC16 CAR-T cells showed more potent antitumor activity than single CAR-T cells in vivo. The present experimental data may support further research work that will have the potential to lead to clinical studies.
\end{abstract}

Keywords: Chimeric antigen receptor T cell, Mucin 16, Programmed cell death-ligand 1, Ovarian cancer

\footnotetext{
* Correspondence: wangjiandongxy@hotmail.com

Department of Gynecologic Oncology, Beijing Obstetrics and Gynecology

Hospital, Capital Medical University, Beijing 100006, China
}

(c) The Author(s). 2020 Open Access This article is licensed under a Creative Commons Attribution 4.0 International License, which permits use, sharing, adaptation, distribution and reproduction in any medium or format, as long as you give appropriate credit to the original author(s) and the source, provide a link to the Creative Commons licence, and indicate if changes were made. The images or other third party material in this article are included in the article's Creative Commons licence, unless indicated otherwise in a credit line to the material. If material is not included in the article's Creative Commons licence and your intended use is not permitted by statutory regulation or exceeds the permitted use, you will need to obtain permission directly from the copyright holder. To view a copy of this licence, visit http://creativecommons.org/licenses/by/4.0/. The Creative Commons Public Domain Dedication waiver (http://creativecommons.org/publicdomain/zero/1.0/) applies to the data made available in this article, unless otherwise stated in a credit line to the data. 


\section{Background}

Epithelial ovarian cancer (EOC) represents approximately $90 \%$ in Ovarian cancer (OC), which is the fifth most common tumor in female malignancies $[1,2]$. EOC is classified as a serous, endometrioid, mucinous, clear cell and unspecified type in the tumor cell histology [3]. More than $50 \%$ of serous carcinoma is the primary type of EOC [4], and it is diagnosed at stage III (51\%) or stage IV $(29 \%)$ due to the absence of specific early symptoms [3]. Due to inadequate screening and detection methods at early stage, more effective and less recrudescent therapies are urgently needed. The current primary treatment of EOC is extensive surgery combined with platinum-based or taxane-based chemotherapy, however, there are limited benefits for improving prognosis [2-4].

CAR-T cell therapy as one of the representative adoptive immunotherapies, has made unprecedented progress in the treatment of hematologic malignancies. The US Food and Drug Administration (FDA) has approved CD19 CAR-T products for acute lymphoblastic leukemia and diffuse-large B cell lymphoma [5]. However, because of the deficiency of tumor-specific targets and physiologic barrier, it is challenging for the patients with solid tumors to receive benefits [6].

Some researchers engineered multiple CAR-T cells on $\mathrm{OC}$ in numerous studies and demonstrated desirable outcomes. For example, the NKG2D-CAR-T cell can specifically recognize and kill the $\mathrm{OC}$ cells expressing NKG2DL antigen [7]. CAR-T cells can recognize and combine with the tumor cells expressing specific antigen via extracellular $\mathrm{scFv}$ fragment [8]. After recognizing the target cells, CAR- $T$ cells release cytokines such as IL-2, IL-6, TNF- $\alpha$, and IFN- $\gamma$ to activate T cells and stimulate NK cells promoting the secretion of various factors that starts a series of killing effect [9]. However, most CAR-T cell has one specific CAR molecule that targets one antigen of the tumor cells, which may cause on-target offtumor toxicity, difficulty in homing, absence of sustaining $\mathrm{T}$ cell effect and cytokine release syndrome (CRS) in vivo $[10,11]$. In addition, single CAR-T cannot improve the tumor microenvironment. The immune escape caused by influence of the tumor microenvironment cannot be avoided [12]. Considering the overall lethal effect and deficiency of single-target CAR-T technology in carcinomas, we hypothesized a CAR-T with higher specificity, i.e. dual-target CAR-T, would address the deficiency while exhibit an enhanced lethal effect on EOC. In structuring valiant dual-target CAR-T, selecting specific antigens as targets are very crucial.

Mucin 16 (MUC16), as the glycoprotein with the highest massive molecule weight in the mucin family, is a critical biomolecule to maintain the intracellular balance and protect the epithelium [13]. It is expressed in a variety of tumor cells and involved in the proliferation and metastasis of tumor cells. Studies have shown that $80 \%$ EOC express MUC16, and its extracellular segment is cut and released in the peripheral blood to be a wellknown tumor marker, namely CA125 [14]. Therefore, we believe that MUC16 is an ideal antigenic target for CAR molecules.

Programmed cell death-1(PD1) is an immunosuppressive molecule widely expressed on the surface of activated $T$ cells, $B$ cells, antigen-presenting cells, and macrophages. It belongs to the $\mathrm{CD} 28 /$ cytotoxic $\mathrm{T}$ lymphocyte-associated antigen-4(CTLA-4) family [15]. PD-1 and its ligand PDL1 constitute the PD1/PDL1 signaling pathway, which plays an inhibitory role in $\mathrm{T}$ cell immunity. Current research suggests that $\mathrm{T}$ cells can secrete cytokines such as IL-10 and IFN- $\gamma$ to induce generation of CTLA ligand, such as PD1 expressing on OC cells. At the same time, PD1 induces expression and combines with inhibitory receptors on the surface of $\mathrm{T}$ cells, therefore reducing the anti-activity of effector $\mathrm{T}$ cells and guiding $\mathrm{T}$ cell reposition or causing $\mathrm{T}$ cell failure to achieve immune escape [16-20]. In the experiment of melanoma-bearing mice, it was found that the up-regulated expression of PDL1 in the tumor microenvironment led to the suppression of anti-tumor immune escape on $\mathrm{T}$ cells. After intraperitoneal injection of the PD1 antibody to block the PD1 pathway, T cell significantly increased infiltration [21-23]. There is also a study that shows the five-year survival rate of patients with low expression of PDL1 is significantly higher than that of patients with high expression of PDL1 [22, 24, 25]. Based on the above research of PD1, we surmise that PDL1 would be another ideal target.

In recent years, more researches have been done on PD1 in various solid tumors, such as breast cancer and prostate cancer. There are evidences that PD1 positively contributes to CAR-T cells function [26, 27]. Liu X et al. demonstrated that when PD1 co-expressed with anti-mesothelin on CAR$T$ cells against multiple solid tumor cells, the PD1 chimera enhanced the effector activity of CAR-T cells in mice model [28]. Therefore, it is reasonable to speculate that the combination of PD1 and anti-MUC16 is one of the best combinations of CAR-T against EOC.

In this study, we developed a novel tandem-specific CAR-T cell that targets MUC16 and PDL1 antigens. We investigated whether the extracellular domain of PD1antiMUC16 CAR-T can effectively recognize the targeted antigens, kill tumor cells, and further release cytokines and prolong the survival time of tumor-bearing mice.

\section{Methods}

\section{Cell lines}

Lenti-X $293 \mathrm{~T}$ cell line was purchased from Clontech (Cat\#632180, California, United States) in August 2018, 
and the test report was provided by Clontech (California, United States). OVCAR-3 cell line was purchased from FuHeng Cell Center (Cat\#FH0726, Shanghai, China) in February 2016. It was tested by STR Authenticated provided by FuHeng Cell Center, and the test report showed a complete match with the NIH: OVCAR-3 (ATCC HTB-161). Umbilical blood mononuclear cell (UBMC) was obtained from healthy donors in Beijing Obstetrics and Gynecology Hospital in March 2019. UBMC was tested for the positive rate of $\mathrm{CD} 3$ on the cell surface by flow cytometry after being activated. All cell lines were validated monthly to be mycoplasma free by PCR. Lenti-X $293 \mathrm{~T}$ cells were used to construct lentiviral expression vectors and were cultured in high glucose DMEM medium (Hyclone, Logan, United States) containing 5\% fetal bovine serum (FBS, Hyclone, Logan, United States) and 1\% penicillin-streptomycin solution (Hyclone, Logan, United States). OVCAR-3 cells were marked as OVCAR3-luc cells by luciferase, culturing in RPMI-1640 medium (Gibco, California, United States) supplemented with $10 \%$ FBS, $1 \%$ penicillinstreptomycin solution, and $0.1 \%$ insulin (Gibco, California, United States). After being activated by anti-CD3/CD28 magnetic beads (Novoprotein, Shanghai, China), UBMC was cultured in the GT-T551 H3 medium (TaKaRa, Osaka, Japan) containing 5\%FBS and $40 \mathrm{IU} / \mathrm{ml}$ IL-2 (Novoprotein, Shanghai, China). All cells were cultured in an incubator (ESCO, Portland, United States) at $37^{\circ} \mathrm{C}$ and $5 \% \mathrm{CO}_{2}$. This study was approved by the Medical Ethics Committee, Beijing Obstetrics and Gynecology Hospital, Capital Medical University (2018-KY-026-01).

\section{Construction of CAR molecule}

After designing the sequences, primers and templates were synthesized by Sangon Biotech. According to the PCR principle, the single chain antibody fragments (scFv) of PD1, anti-MUC16 and PD1-antiMUC16 CAR were obtained. The main structures of PD1 and antiMUC16 are PD-1etco and 4H11-VH-(Gly4Ser)3-4H11VL. The primary structure of PD1-antiMUC16 is tandem of PD1 and anti-MUC16. The three scFv fragments were cloned into the pLVX-EFl $\alpha$-IRES-mCherry plasmid (Clontech, California, United States) through EcoR I and Mlu I cloning sites and named PD1antiMUC16 CAR, anti-MUC16 CAR, and PD1 CAR, respectively. The plasmid has been genetically engineered to be a second-generation CAR containing CD8a hinge region, CD8 transmembrane region, 4-1BB costimulation domain, and $\mathrm{CD} 3 \zeta$ domains. The plasmids were amplified in bacterial solution, and the positive samples were selected by agarose gel electrophoresis and verified via sequencing analysis.

\section{Lentivirus packaging}

Set the experiment groups (pLV-PD1-anti-MUC16, pLV-anti-MUC16, and pLV-PD1) and Control group (control T). In each group, $13.7 \mu \mathrm{g}$ plasmid was taken and mixed with packaging plasmid containing $3.43 \mu \mathrm{g}$ pMD2.G, $3.43 \mu \mathrm{g} \quad \mathrm{pMDLg} / \mathrm{pRRE}, \quad 3.43 \mu \mathrm{g}$ pRSV-Rev (Addgene, Massachusetts, United States) to make DNAmix. $7 \times 10^{6}$ cells Lenti-X $293 \mathrm{~T}$ were added into the DNA-mix and the same volume of polyethylenimine (PE1, Polyscience, Pennsylvania, United States), then cultured in the incubator. Fresh virus packaging medium containing Opti-MEM (Gibco, California, United States), 5\% FBS, 1\% L-glutamine (Gibco, California, United States), $1 \%$ sodium pyruvate (Gibco, California, United States), and $0.2 \%$ penicillin-streptomycin solution was supplemented after $6 \mathrm{~h}$ of culturing. After $24 \mathrm{~h}$, we collected supernatant and obtained virus concentrate $(210 \mu \mathrm{L})$, from which $6 \mu \mathrm{L}$ was taken to infect $293 \mathrm{~T}$ cells again for virus titer detection. The rest of the virus concentrate was stored in a $4{ }^{\circ} \mathrm{C}$ refrigerator for preparation of CAR-T cells. After $48 \mathrm{~h}$ of infection, the infected cells were placed into 12-well plates (Corning, New York, United States). $5 \mu \mathrm{L}$ Percp-cy5.5 antihuman PD-1 antibody (BD, New jersey, United States), and $10 \mu \mathrm{L}$ FITCProtein L antibody (ACRO, Delaware, United States) were added to each well, and incubated in the dark for $30 \mathrm{~min}$. The flow cytometry (NovoCyte Advanteon, ACEA, Hangzhou, China) was used to detect the positive rate of PD1 and anti-MUC16 in Lenti-X 293 T cells. The viral titer was calculated according to the following formula:

Viral Titer $(\mathrm{TU} / \mathrm{ml})=\frac{(\text { Number of Infected Cells } \times \text { Positive Rate })}{\text { Viral Volume }(\mathrm{ul})} \times 1000$

\section{T cell transduction}

Set the experiment groups (pLV-PD1-anti-MUC16, pLV-anti-MUC16, and pLV-PD1) and Control group (control T). After thawing, $2.5 \times 10^{6} \mathrm{UBMC}$ were added into phosphate buffer saline (PBS, Hyclone, Logan, United States) with a volume of 10 times, which was then centrifuged at $1000 \mathrm{rpm}$ for $15 \mathrm{~min}$ (BT-320C, Baiyang, Beijing, China). Then an appropriate $\mathrm{T}$ cell complete medium and $25 \mu \mathrm{L}$ magnetic beads were added. The mixture was cultured in the incubator for $48 \mathrm{~h}$. Lentiviral supernatants were collected, of which $200 \mu \mathrm{L}$ per well was added into the 12 -well plate coated with $200 \mu \mathrm{g}$ NovoNectin (Novoprotein, Shanghai, China) overnight. Meanwhile, control $\mathrm{T}$ well was added with $200 \mu \mathrm{L}$ GT-T551 H3 medium. All wells were added with $800 \mu \mathrm{L}$ UBMC $\left(2.5 \times 10^{5}\right.$ cells/well $)$ and cultured in an incubator. After culturing for $6 \mathrm{~h}, 2 \mathrm{~mL}$ of T cells complete growth medium (GT-T551 H3 + 5\%FBS + 40 IU/ml IL-2) was added and $\mathrm{T}$ cells were re-infected for the following 
day. After the second infection for $96 \mathrm{~h}, 1 \times 10^{6}$ cells was taken out from each well, washed twice with PBS, removed of the magnetic beads, and stained with $5 \mu \mathrm{L}$ Percp-cy5.5 antihuman PD-1 antibody and $10 \mu \mathrm{L}$ FITCProtein L antibody for $30 \mathrm{~min}$ in the dark. Then it is followed by washing with PBS twice and detection for the positive rate of CAR structure by the flow cytometry. Finally, when CAR-T cells were successfully prepared, the positive ratio of the other two CAR-T cells was adjusted according to the lowest positive ratio of three CAR molecules by increasing the number of control $\mathrm{T}$ cells.

\section{Preparation of target cells}

After thawing, OVCAR3-luc cells were cultured in RPML1640 medium containing 20\% FBS, 1\% glutamine, $1 \%$ sodium pyruvate, $1 \%$ penicillin and streptomycin, $0.01 \mathrm{mg} / \mathrm{mL}$ insulin. It was seeded in T25 bottle with a density of $5 \times 10^{5} / 4 \mathrm{~cm}^{2}$ in an incubator $\left(37^{\circ} \mathrm{C}, 5 \% \mathrm{CO}_{2}\right)$. Both MUC16 plasmid and PDL1 plasmid (Juventas, Tianjin, China) were mixed with the PEI-DNA mix to complete lentiviral packaging by PEI transfection, and were harvested for MUC16 lentiviral expression vector, PDL1 lentiviral expression vector, and MUC16-PDL1 lentiviral expression vector. The lentiviral concentrate was harvested at $24 \mathrm{~h}$ and $48 \mathrm{~h}$, followed by infecting OVCAR3-luc cells. Flow cytometry measured the positive rate of MUC16 and PDL1 on the OVCAR3-luc cell surface after $96 \mathrm{~h}$ of re-infection.

\section{Flow Cytometry}

One million CAR-T cells were stained with $5 \mu \mathrm{L}$ Percpcy5.5 antihuman PD-1 antibody and $10 \mu \mathrm{L}$ FITC-Protein $\mathrm{L}$ antibody for an antigen-antibody binding reaction. After 30 min of dark incubation, dissociative antibodies uncombined with antigens were washed by PBS. CAR molecule expression was measured for fluorescence intensity by flow cytometry. This method was used to detect viral titer and transfection rate of $\mathrm{T}$ cell. The cytotoxicity of CAR-T cells was evaluated via detecting the luciferase expression of tumor cells after stained with $70 \mu \mathrm{L}$ Steady-Glo. Simultaneously, the transfection efficiency of tumor cells was evaluated via detecting green fluorescent protein (GFP).

\section{Enzyme-linked Immunosorbent assay (ELISA)}

The human IFN-gamma ELISA kit, IL-2 ELISA kit, and TNF-alpha ELISA kit (all kits, Dakewe, Beijing, China) were used to measure the concentrations of IFN- $\gamma$ and IL-2, TNF- $\alpha$, respectively. According to the instructions of the ELISA kit, three samples were processed, and the standard curve was prepared. Then the fluorescence value was measured by the enzyme-labeled instrument
(TECAN, Mannedorf, Switzerland). The cytokines quantity was then calculated.

\section{Cytotoxicity assay and cytokine release assay}

Target cells: OVCAR3-luc cells, OVCAR3-PDL1-luc cells, OVCAR3-MUC16-luc cells, and OVCAR3MUC16-PDL1-luc cells; Effector cells: PD1-antiMUC16 CAR-T cells, antiMUC16 CAR-T cells, PD-1 CAR-T cells, control $\mathrm{T}$ cells (negative group). Target cells was adjusted for a density of $2 \times 10^{5}$ cells $/ \mathrm{mL}$ by GT-T551 $\mathrm{H} 3$, and seeded into the black flat 96-well U-bottomed plate $(50 \mu \mathrm{L} /$ well $)$. Effector cells were adjusted for a density of $3.2 \times 10^{6}$ cells/mL by GT-T551 H3, and seeded into the same 96 -well plate $(50 \mu \mathrm{L} /$ well $)$ at effector to target(E/T) ratios of $1: 1,4: 1,8: 1$ and $16: 1$, respectively. Simultaneously, target cells $(50 \mu \mathrm{L} /$ well $)$ were cultured alone and with $50 \mu \mathrm{L}$ GT-T551 H3 medium. The plate was put in the incubator at $37^{\circ} \mathrm{C}$ for $4 \mathrm{~h}$. Afterwards, all cells were stained with $70 \mu \mathrm{L}$ Steady-Glo (Promega, Wisconsin, United States) per well for $20 \mathrm{~min}$ in the dark. The fluorescence value was detected by flow cytometry and the killing rate of various CAR-T cells on tumor cells was calculated according to the following formula:

Killing Rate $\%=\frac{(\text { Fluorescencemax of target cells }- \text { Fluorescence of experimental well })}{\text { Fluorescencemax of target cells }} \times 100 \%$

The CAR-T cells were co-cultured with target cells, at 1:1 ratio $\left(1 \times 10^{4} \mathrm{~T}\right.$ cells and $1 \times 10^{4}$ target cells $)$ in a $\mathrm{V}$ bottomed 96-well plate for $48 \mathrm{~h}$ in the incubator, followed by harvesting supernatant through centrifugation $(2500 \mathrm{rpm}, 5 \mathrm{~min})$, and detection for the release of IFN- $\gamma$, IL-2, TNF- $\alpha$, respectively by ELISA kit.

\section{Xenograft mice models for in vivo treatment}

All animal studies were approved by the Medical Ethics Committee, Beijing Obstetrics and Gynecology Hospital, Capital Medical University (2018-KY-026-01). In-house bred NPG mice (NOD.Cg-PrkdcscidIl2rgtm1Vst/Vst) were obtained from Beijing Vitalstar Biotechnology Co., Ltd. Twenty healthy NPG mice (females, 35-41 days old, $18-21 \mathrm{~g}$ in weight) were raised in specific pathogen-free (SPF) conditions and fed with autoclaved food and water. For the xenograft models, NPG mice were intraperitoneally injected with $5 \times 10^{5}$ OVCAR3-MUC16GFP-PDL1-luc cells and $50 \mu \mathrm{L}$ Matrigel (Corning, New York, United States). After $48 \mathrm{~h}$, mice were intraperitoneally injected with $100 \mu \mathrm{L}$ D-Luciferin and Postassium Salt (Sciencelight, Shanghai, China) for 6 min before being put in an isoflurane-oxygen mixture gas anesthetic box containing 3\% isoflurane (RWD, Shenzhen, China) for $2 \mathrm{~min}$. The tumor burden was then measured by IVIS Spectrum and analyzed by Living Image, version 4.3, software (Perkin Elmer). The study subjects were 
distributed randomly into four groups $(n=5$ for each group) on day 0 , and each group was intraperitoneally injected with CAR-T cells $\left(1 \times 10^{6}\right.$ cells per mouse). Imaging was performed on days 7, 14, 21 and 28 to monitor the tumor changes. Mice were euthanized by carbon dioxide asphyxiation when tumour volume exceeded $2000 \mathrm{~mm}^{3}$, when the weight loss over $20 \%$, or when they lost their ability to eat autonomously. The mice were placed in a transparent box that released pure carbon dioxide after conformed to the above criteria. When mice were observed to faint, carbon dioxide continued to be released for $2 \mathrm{~min}$ for euthanization. The survival time of each mouse was recorded and the survival curve by GraphPad Prism 8.3.0 software drawn.

\section{Statistical analysis}

Statistical analysis was performed using SPSS 23.0 software. Data are shown as mean \pm 1 standard deviation (SD). For the in vitro killing assay, the significance of different groups was determined using nonparametric tests. For the in vivo assay, Student's t-test was used to distinguish the difference between groups. The value of $P<0.05$ was considered significant. The mice survival curve was drawn using GraphPad Prism 8.3.0 software.

\section{Results}

\section{Construction of dual-target CAR-T cells by Lentiviral vector transduction}

According to the above protocol, we designed the PD1antiMUC16 CAR molecule structure, which comprised PD1-antiMUC16 or PD1 or anti-MUC16 extracellular $\mathrm{scFv}$ fragment, a hinge region, a transmembrane domain, followed by intracellular 4-1BB co-stimulation domain and $\mathrm{CD} 3 \zeta$ domain. In addition, the $\mathrm{scFv}$ fragment contained three parts, i.e., PD1 ecto, 4H11-VH (heavy chain) and $4 \mathrm{H} 11-\mathrm{VL}$ (light chain). These three parts were connected by the linker peptide (Gly4Ser) 3 that constructed the $2000 \mathrm{bp}$ dual-target CAR molecule (Fig. 1a). Through gene recombination, CAR molecule sequences combined with the $9367 \mathrm{bp}$ lentiviral vector, which were digested by two enzymes (EcoR I and Mlu I) (Fig. 1b). Via testing by agarose gel electrophoresis, PD1, antiMUC16, PD1-antiMUC16, and plasmid skeleton fragment bands were observed at $510 \mathrm{bp}, 1500 \mathrm{bp}, 2000 \mathrm{bp}$, and 7435 bp, respectively (Fig. 2a), and original gel electrophoresis was in Additional file 1 (Figure S1). Meanwhile, the sequence of the positive samples was analyzed and verified to be entirely consistent with the designed one (Fig. 2b). The plasmids were transferred into LentiX $293 \mathrm{~T}$ cells to package lentivirus by polyetherimide (PEI) transfection. Anti-MUC16 and PD1 antigen were combined with $10 \mu \mathrm{L}$ FITC-Protein L antibody and $5 \mu \mathrm{L}$ Percp-cy5.5 antihuman PD-1 antibody, respectively, followed by detection of positive rate of CARs by flow cytometry. Thereout, we harvested the favorable rates of PD1-antiMUC16 CAR, PD1 CAR, and antiMUC16 CAR on the surface of Lenti-X $293 \mathrm{~T}$ cells, which were 10.45, 3.56 , and $18.54 \%$, respectively (Fig. 3). Three viral titers were obtained respectively: $6.27 \times 10^{7} \mathrm{TU} / \mathrm{mL}, 2.14 \times$ $10^{7} \mathrm{TU} / \mathrm{mL}$, and $1.11 \times 10^{8} \mathrm{TU} / \mathrm{mL}$ according to the Formula (1). Utilizing the same detection methods, the infection rates of PD1-antiMUC16 CAR-T cells, PD1 CAR-T cells, and anti-MUC16 CAR-T cells were obtained (52.36, 46.03, and 86.24\%, respectively) (Fig. 3). It indicated that CAR-T cells with single- and dual-targets were successfully constructed.

Overexpressing MUC16 and PDL1 antigens of target cells Based on the above principles and methods with PCR, genic recombination, lentiviral vector transduction, we acquired the $4.40 \%$ positive rate of PDL1 molecule on the surface of the Lenti-X $293 \mathrm{~T}$ cell after combining with $5 \mu \mathrm{L}$ Percp-cy5.5 antihuman PD-1 antibody for 30 min in the dark (Fig. 4a). The lentiviral titer was $2.64 \times$ $10^{7} \mathrm{TU} / \mathrm{mL}$, according to the Formula (1). The infection rate of the PDL1 structure on OVCAR3-luc cell was achieved at $40.72 \%$ (Fig. 4a). The population that consists of OVCAR3-PDL1-luc cells and unstructured cells was named a pool. The positive samples were cultured and proliferated, followed by purification to $100 \%$ (No.3 monoclonal sample) (Fig. 4a). Meanwhile, the lentiviral titer of MUC16 in the MUC16 group was $1.24 \times 10^{8} \mathrm{TU} /$ mL. MUC16-GFP in the OVCAR3-MUC16-GFP-luc pool was selected based on the expression GFP with the MUC16 monoclonal sample purified to 99.93\% (Fig. 4b). The MUC16-GFP positive rate was $94.70 \%$. Moreover, we created MUC16-PDL1 antigen via structuring the PDL1 directly on the monoclonal sample of MUC16. The lentiviral titer of PDL1 in MUC16-PDL1 group was $2.52 \times 10^{7} \mathrm{TU} / \mathrm{mL}$, and the positive rate of PDL1 on OVCAR3-MCU16-GFP-luc pool was $84.68 \%$ with the PDL1 depurated to $99.75 \%$ (Fig. 4c). OVCAR3-luc cell lines overexpressing MUC16 and PDL1 antigens were successfully constructed, and the positive rate of tumor cell surface antigen was over $99 \%$.

\section{Functional activity of CAR-T cells in vitro}

To ascertain the cytotoxicity of CAR-T cells against MUC16 or PDL1 positive cancer cells in vitro, we cocultured CAR-T cells and cancer cells $\left(1 \times 10^{4}\right.$ cells/well $)$ at 1:1, 4:1,8:1, 16:1 ratio. We performed killing assay of PD1-antiMUC16, PD1, and anti-MUC16 CAR-T cells on various target cells for $4 \mathrm{~h}$. The assay indicated that the dual-target CAR-T cells exhibited more potent cytotoxicity than control $\mathrm{T}$ cells against any target cell $(P<$ $0.05)$, and the capacity was enhanced with the increase of $\mathrm{E} / \mathrm{T}$ ratio $(\mathrm{P}<0.05)$. The killing rates of $\mathrm{PD1}$ antiMUC16 CAR-T cell on OVCAR3-MUC16-GFP- 


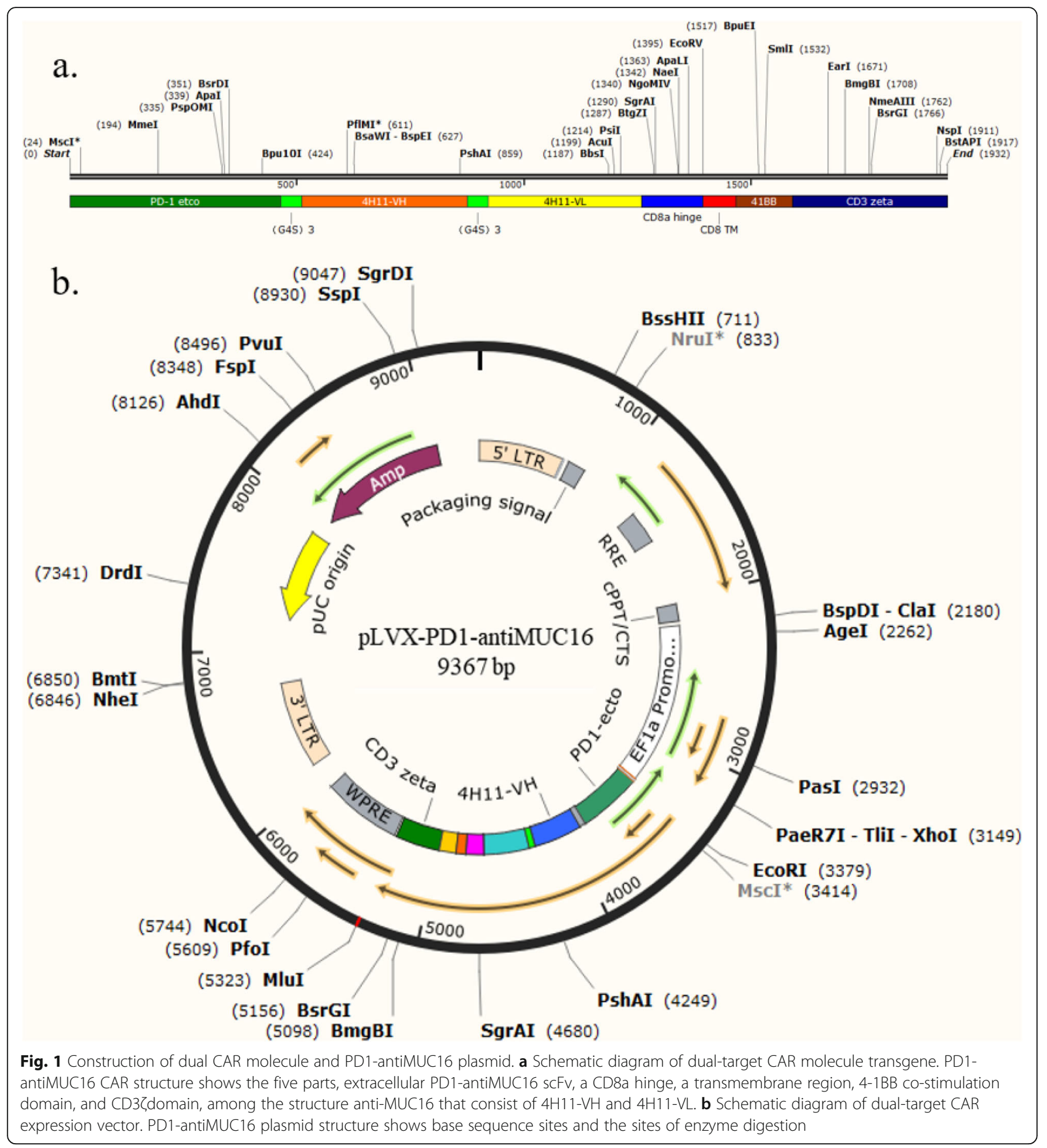

PDL1-luc cells were $12.03 \pm 1.98 \%, \quad 38.29 \pm 0.13 \%$, $65.16 \pm 0.95 \%$, and $84.96 \pm 0.53 \%$ at $\mathrm{E} / \mathrm{T}$ ratios of $1: 1,4: 1$, $8: 1$, and $16: 1$, respectively. Comparatively, the killing rates of the control $\mathrm{T}$ cells was $3.90 \pm 2.76 \%, 9.74 \pm$ $0.13 \%, 12.20 \pm 0.95 \%$, and $17.56 \pm 0.75 \%$, respectively. Meanwhile, single-target CAR-T cells, PD1 and antiMUC16 CAR-T remained almost the same cytotoxicity efficacy with dual CAR-T cell (Fig. 5).
In cytokine release test to assess whether CAR structure enhanced the anti-tumor activity of T cells, cocultures were established between CAR-T cells and target cells at 1:1 ratio $\left(1 \times 10^{4} \mathrm{~T}\right.$ cells versus $1 \times 10^{4}$ cancer cells) in a V-bottomed 96-well plate for $48 \mathrm{~h}$ in incubator. The results revealed all CAR-T cells exerted a more robust capacity of secreting IL-2, IFN- $\gamma$, and TNF- $\alpha$ (Fig. 6) which were harvested from the supernatants and 


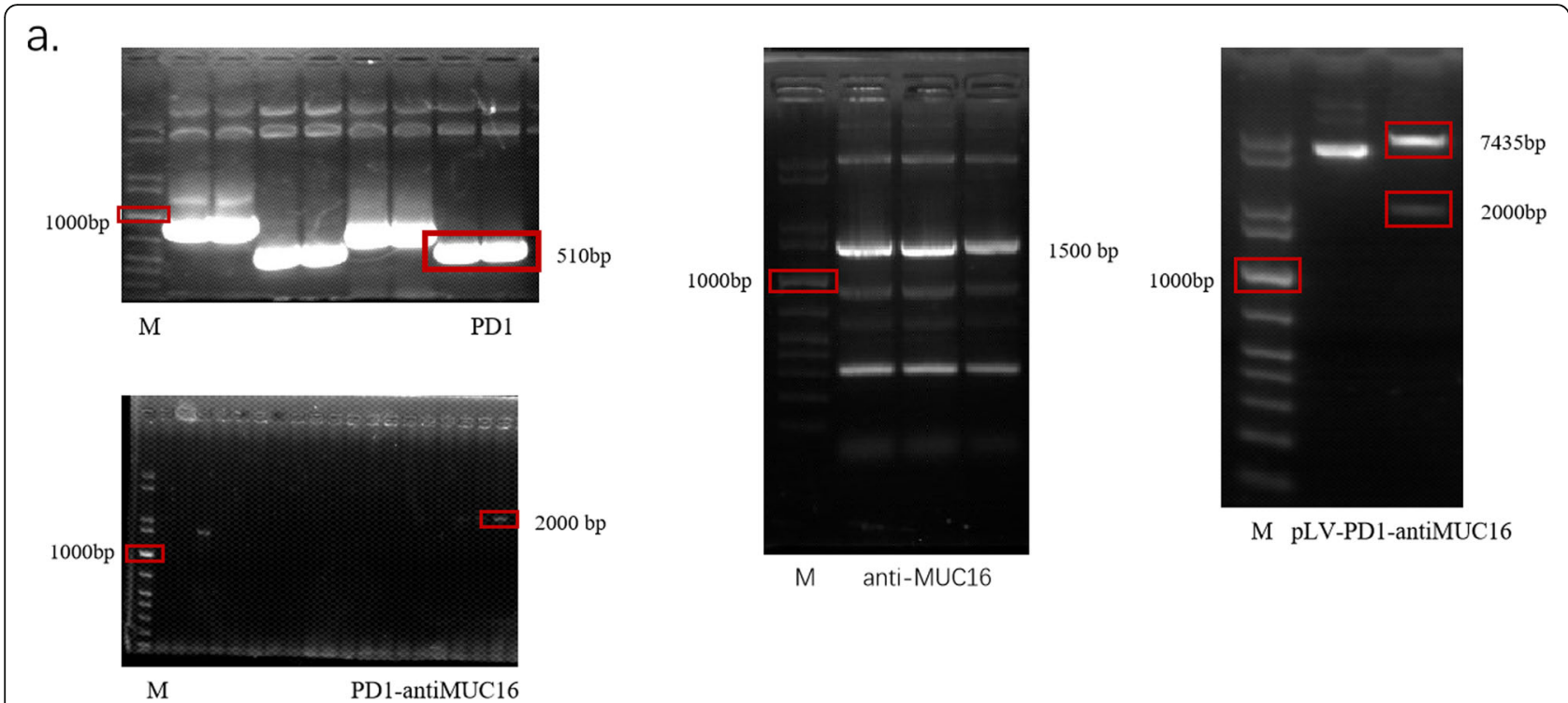

b.

pLV-PD1-antiMUC16

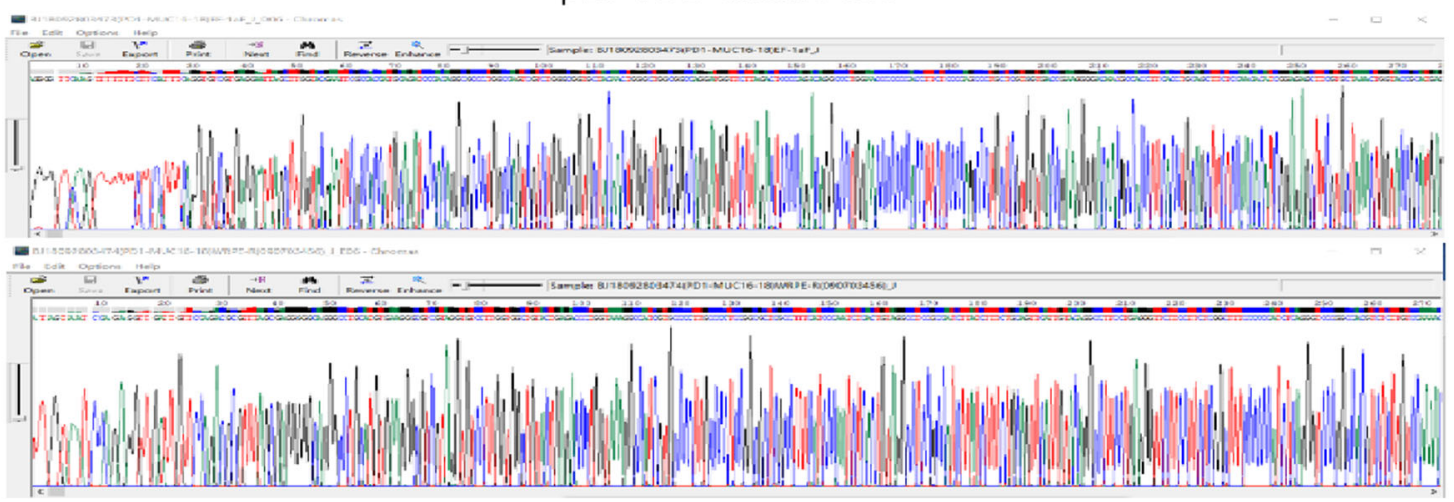

Fig. 2 Detection results of PD1-antiMUC16 CAR by agarose gel electrophoresis and sequencing. a CARs detected by agarose gel electrophoresis, $M$ represents $1 \mathrm{~Kb}$ marker, the right bands of PD1, anti-MUC16, and PD1-antiMUC16 CARs were circled in red. $\mathbf{b}$ The base sequence of the PD1antiMUC16 CAR structure is quite correct. The full-length gels are presented in Additional file 1: Figure S1

measured by ELISA kits. Disappointingly, dual CAR-T cells did not reveal higher levels of cytokines production than single CAR-T cells.

\section{Functional activity of CAR-T cells in vivo}

In order to determine the efficacy of CAR-T cells against ovarian cancer cells in vivo, we established intraperitoneal tumor-bearing models using NPG mice, which were injected with OVCAR3-MUC16-GFP-PDL1-luc cells $\left(5 \times 10^{5}\right.$ cells) and $50 \mu \mathrm{L}$ Matrigel into the abdominal cavity and raised $48 \mathrm{~h}$. As shown in Fig. 7a, all mice appeared well-distributed with stable size tumors. They were measured for fluorescence values by IVIS Spectrum and analyzed for the pre-therapeutic evidence of tumor by Living Image.

Tumor-bearing mice models were randomized into four groups ( $n=5$ per group) and injected with CAR-T cells $\left(1 \times 10^{6}\right.$ cells $)$ into the abdominal cavity on day 0 .
The fluorescence values was then measured weekly to monitor the progress of the tumor. Dual CAR-T exhibited significant regression of ovarian cells as detected on day 7 to day 14 (Fig. 7b, c), followed by slow proliferation. However, two single CAR-T groups did not show the potent therapeutic effect as dual CAR-T cell did, with the progress of the tumor restrained instead. From all models, we discovered that the best treatment efficiency was shown for the first week after injecting CAR$\mathrm{T}$ cells (Fig. 7d). This may help establish the dose and frequency of future safety and clinical trials.

As time passed, all four groups of mice died for ovarian cancer; however, their tumor-bearing survival time was different. The dual CAR-T group demonstrated exceptionally longer survival time of mice than the single CAR-T groups and control group. The mean survival time of dual CAR-T group reached to $80.6 \pm 10.33$ days. Whereas for two single CAR-T groups, the mean 


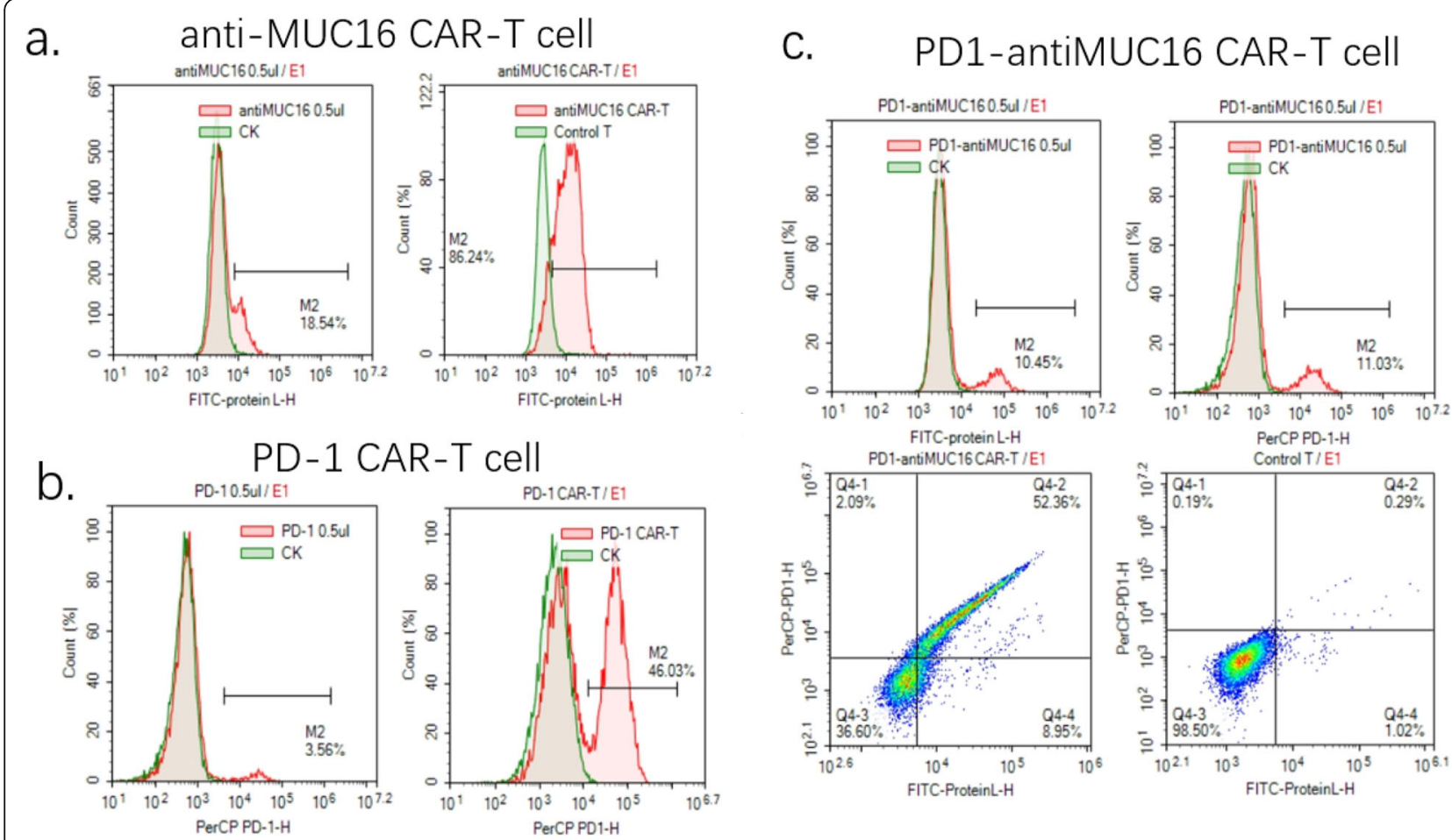

Fig. 3 Detection results of the positive rate of single and dual CARs on T cells. a The testing results of viral titer and infection rate of anti-MUC16 CAR-T cell. Anti-MUC16 CAR-T cells stained with $10 \mu \mathrm{L}$ FITC-Protein $L$ antibody for $30 \mathrm{~min}$ in the dark, followed by detecting via flow cytometry. The green peak is the control group, and the red peak is the experimental group. $\mathbf{b}$ The detecting results of viral titer and infection rate of PD1 CAR-T cell. PD1 CAR-T cells stained with $5 \mu \mathrm{L}$ Percp-cy5.5 antihuman PD-1 antibody for $30 \mathrm{~min}$ in the dark, followed by detecting via flow cytometry. $\mathbf{c}$ The testing results of viral titer and infection rate of PD1-antiMUC16 CAR-T cell. Control T showed both negative results stained with two antibodies. However, PD1-antiMUC16 CAR-T showed both positive results with two antibodies

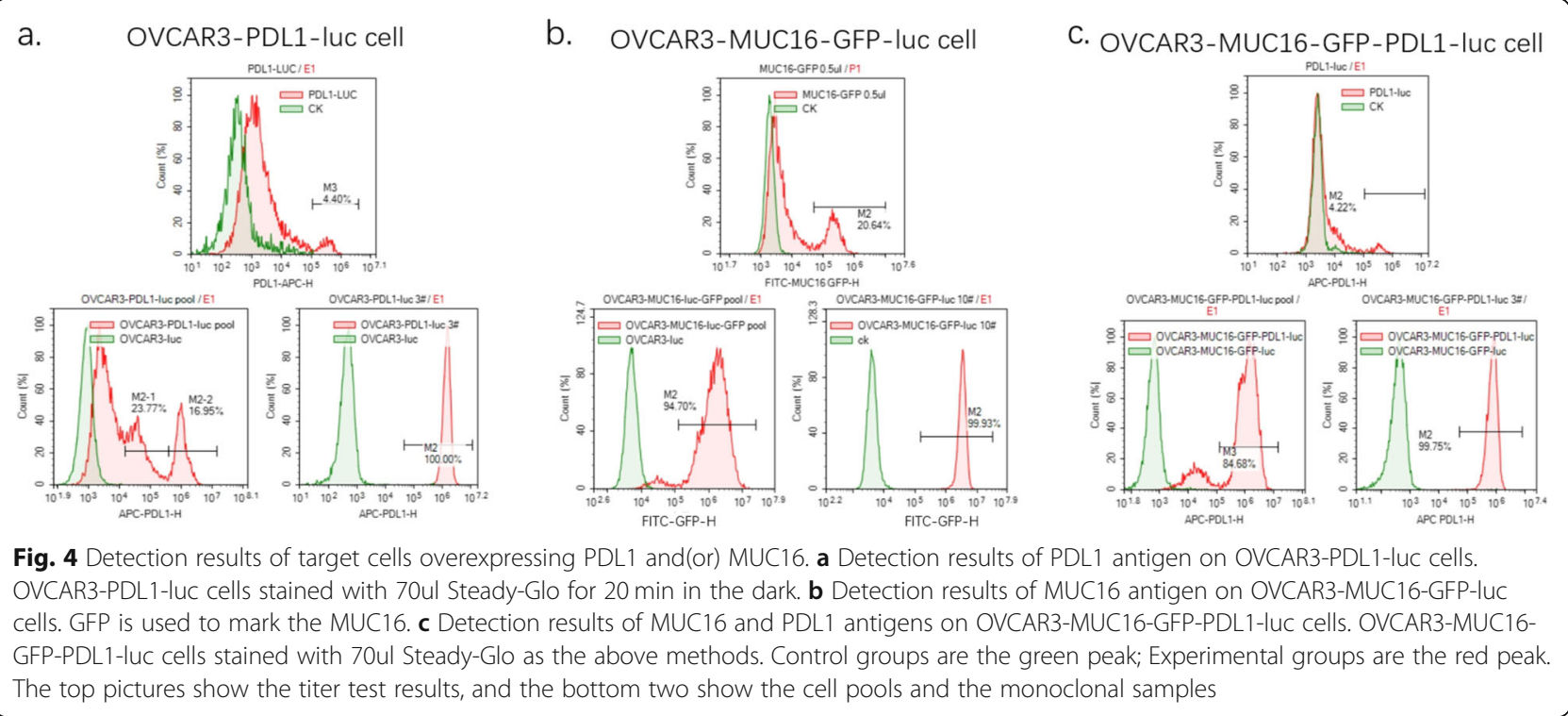


a.

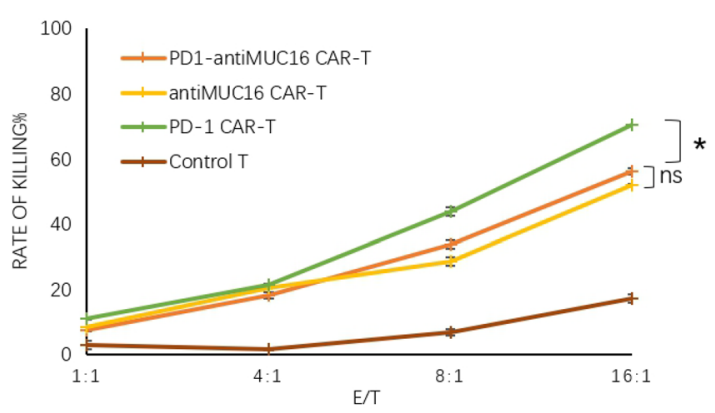

C.

\section{OVCAR3 - PDL1-LUC}

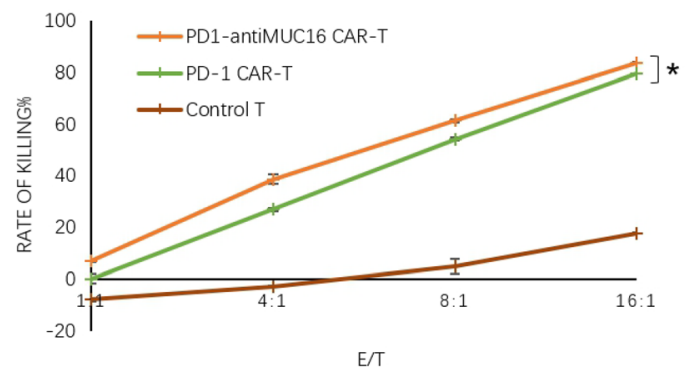

b.

OVCAR3-MUC16-GFP-LUC

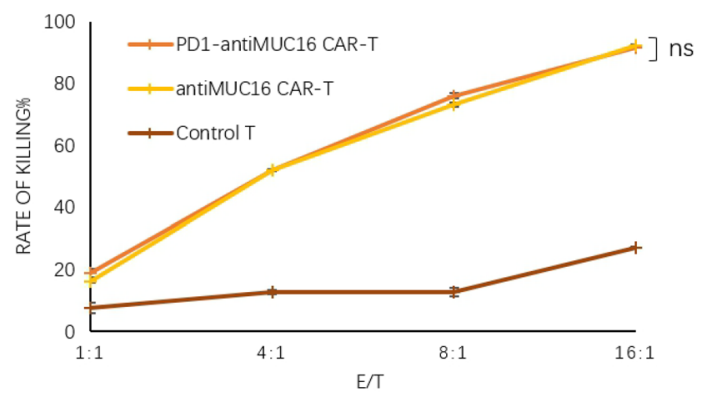

d.
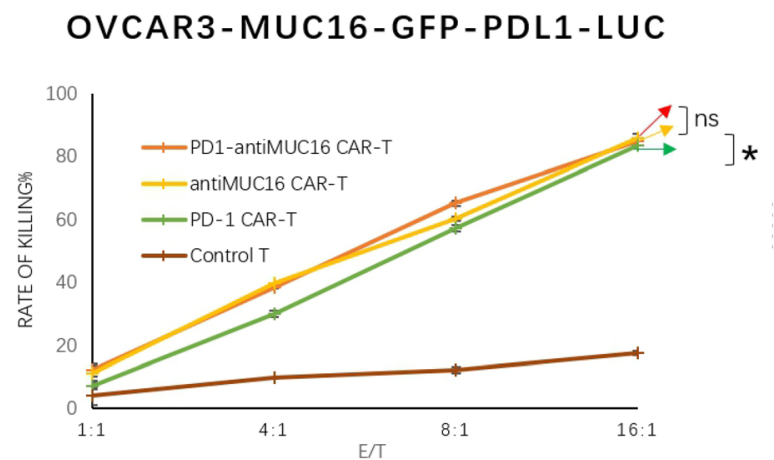

Fig. 5 The antitumor activity results in single and dual CAR-T cells against various target cells. There are four kinds of tumor cells expressing PDL1 and(or) MUC16 antigen or not, and four different T cells expressing PDL1 and(or) antiMUC16 or not. The CAR-T cells co-cultured for $4 \mathrm{~h}$ with target cells $\left(1 \times 10^{4}\right)$ at $E / T$ of 1:1,4:1,8:1, and 16:1 in a total volume of $100 \mathrm{ul}$, after that stained with $70 \mu \mathrm{L}$ Steady-Glo for 20 min and detected by flow cytometry. Data show the mean $\pm S D$, and the results were analyzed with the nonparametric test. Error bars represent the SD. ns: $P>0.05$, *: $p<0.05$

survival times of PD1 CAR-T group and antiMUC16 CAR-T group were $45.2 \pm 6.34$ days and $23.0 \pm 1.55$ days, respectively. The control group had the shortest survival time of $19.8 \pm 2.14$ days (Fig. 7e). From the perspective of extending the lifetime of tumor-bearing mice, the dual CAR-T group demonstrated the higher capacity of prolonging the survival time of mice than others $(P<$ 0.01) (Fig. 7e).

\section{Discussion}

The aggressive ovarian cancer as the exceptionally highgrade serous carcinoma is deemed as an urgent medical challenge in the twenty-first century due to the low fiveyear survival time, rapidly invasive progression and high recurrence rate. CAR- $\mathrm{T}$ technology has exhibited feasible antitumor activities in hematologic malignancies with a potential in the treatment of OC. However, the paucity of specific antigens and the immune escape of $\mathrm{OC}$ are the primary obstacle.

In our study, in order to increase the target specificity and reduce immune escape, we adopted a tandem structure in design of CAR molecule for two antigenic targets using second-generation CAR-T conception. The results indicated that both two CARs showed antitumor activity rather than interacting with each other, which may be attributed to the hinge domain supplying space for $\mathrm{scFv}$ folding [29-31]. MUC16 and PDL1 are undoubtedly ideal target antigens for CAR-T technology against OC in our study. Additionally, both dual CAR-T cells and single CAR-T cells showed favorable cytotoxic efficiency against various devised OVCAR-3 cells in vitro, especially at a high E/T ratio. The destructive effect of dual CAR-T cells is not superior to that of the single CAR-T cells. Although there is no apparent difference between the dual CAR-T cell and single CAR-T cell in cytotoxicity and cytokines production in vitro, dual CAR-T demonstrated remarkable tumor therapeutic effect in vivo and prolonged survival time of tumor-bearing mice models as compared with that of single CAR-T cells.

To understand why dual CAR-T cells exhibited disparity tumor therapeutic effects for in vivo and in vitro, the critical point to consider may be the fact that PD1 recognizes target antigens, which are correlated with the tumor microenvironment. This environment which is not developed in vitro may have facilitated the high therapeutic effect in vivo. This assumption was supported by the assay results. PD1 CAR-T exhibited potent 

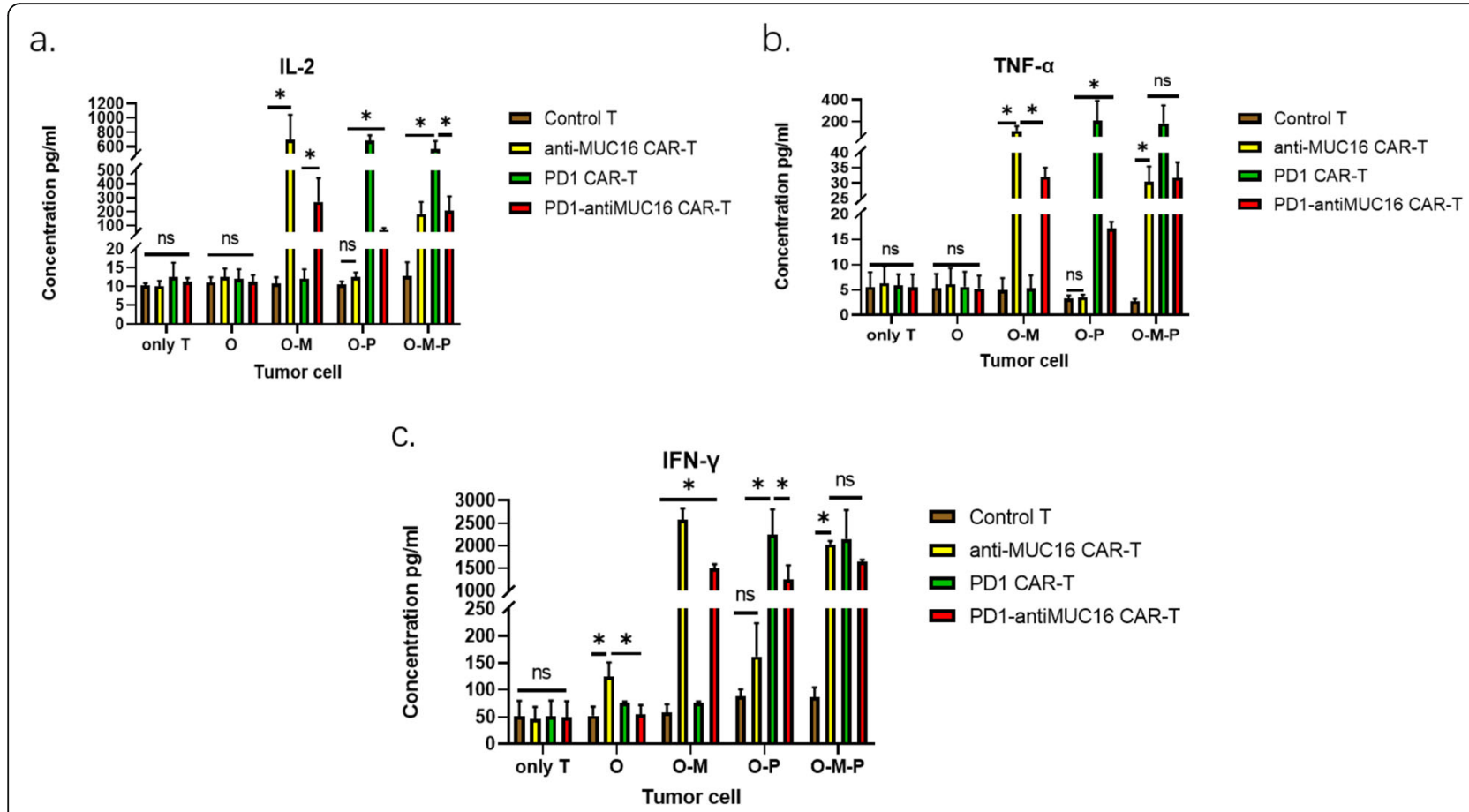

Fig. 6 Three cytokines production by effector cells in response to various OVCAR-3 cell lines. Four effector cells (PD1-antiMUC16 CAR-T cells, PD1 CAR-T cells, anti-MUC16 CAR-T cells and T cells without CAR molecule) co-cultured with four kinds of OVCAR-3 cells (OVCAR3-luc cells, OVCAR3MUC16-GFP-luc cells, OVCAR3-PDL1-luc cells, and OVCAR3-MUC16-GFP-PDL1-luc cells) at 1:1 ratio for $48 \mathrm{~h}$ to explore the different secretion capacities of IL-2, IFN- $\gamma$, and TNF-a between four T cells. These cytokines tested by ELISA kits. Only T: without target cells, O: OVCAR3-luc cell, O-M: OVCAR3-MUC16-GFP-luc cell, O-P: OVCAR3-PDL1-luc cell, O-M-P: OVCAR3-MUC16-GFP-PDL1-luc cell, -:The groups covered by horizontal line are compared in pairs. Data show the mean \pm SD, and the results were analyzed with the nonparametric test. Error bars represent the SD.ns: $P>0.05$, *: $p<0.05$

cytotoxicity in mice models and significantly prolonged the survival, especially against OVCAR3-PDL1-luc cells and OVCAR3-MUC16-GFP-PDL1-luc cells. The assay results indicated a significant attack capability of CAR-T cells against target cells impacted by the surrounding environment. In the experimental design, PD1-antiMUC16 CAR-T were constructed as the experimental group, while PD1 CAR-T and anti-MUC16 CAR-T were used as the positive control, and control $\mathrm{T}$ without any CAR structure was used as the negative control. Additionally, PDL1 antigen was induced in up-regulation by activated $\mathrm{T}$ cells in vivo rather than high natural expression. We established a variety of tumor cells, i.e., OVCAR-3 cells, OVCAR3-PDL1-luc cell, OVCAR3-MUC16-GFP-luc cell, and OVCAR3-PDL1-MUC16-GFP-luc cells to better simulate antigenic expression in OC patients. To build a desirable model that will exclude the impact of different antigen expression rates in patients and simulate the condition in vivo, we constructed the OVCAR3PDL1-MUC16-GFP-luc tumor-bearing mice model. It is also worth noting that immunosuppressive tumor microenvironment existing in tumor-bearing mice nay partially imitate the human condition but still quite different. We acknowledge further animal studies are needed to demonstrate the advantage of CAR-T technology.

Another factor that may impact the activity of CAR-T cells is the spatial conformation of extracellular domains. Leonard Leong et al. verified that the structure of the part behind the antigen-recognize region and its length could affect the activity of CAR-T cells [32]. Based on this finding, the cytotoxicity of CAR-T cells may be related to the composition and spatial conformation of extracellular domains. The prospect to optimize the CAR molecules by exploring the spatial conformation of extracellular domains appears promising.

There are indeed knowledge gaps in research, such as how to reduce the CRS, improve homing, and keep consistency in OC patients. Previously, some researchers had proposed that selecting target antigens with high specificity, optimizing the function of CAR-T cells, and blocking immunosuppressive molecules such as PD1/ PDL1 signal, could reduce the occurrence of CRS [3337]. Moreover, combining higher specific CAR-T cells with chemokine receptors may improve homing and enhance therapeutic activity [6]. On the other hand, some researchers believe that CAR-T does not lead to CRS and other side effects. Wen $\mathrm{H}$ et al. verified that CAR- 


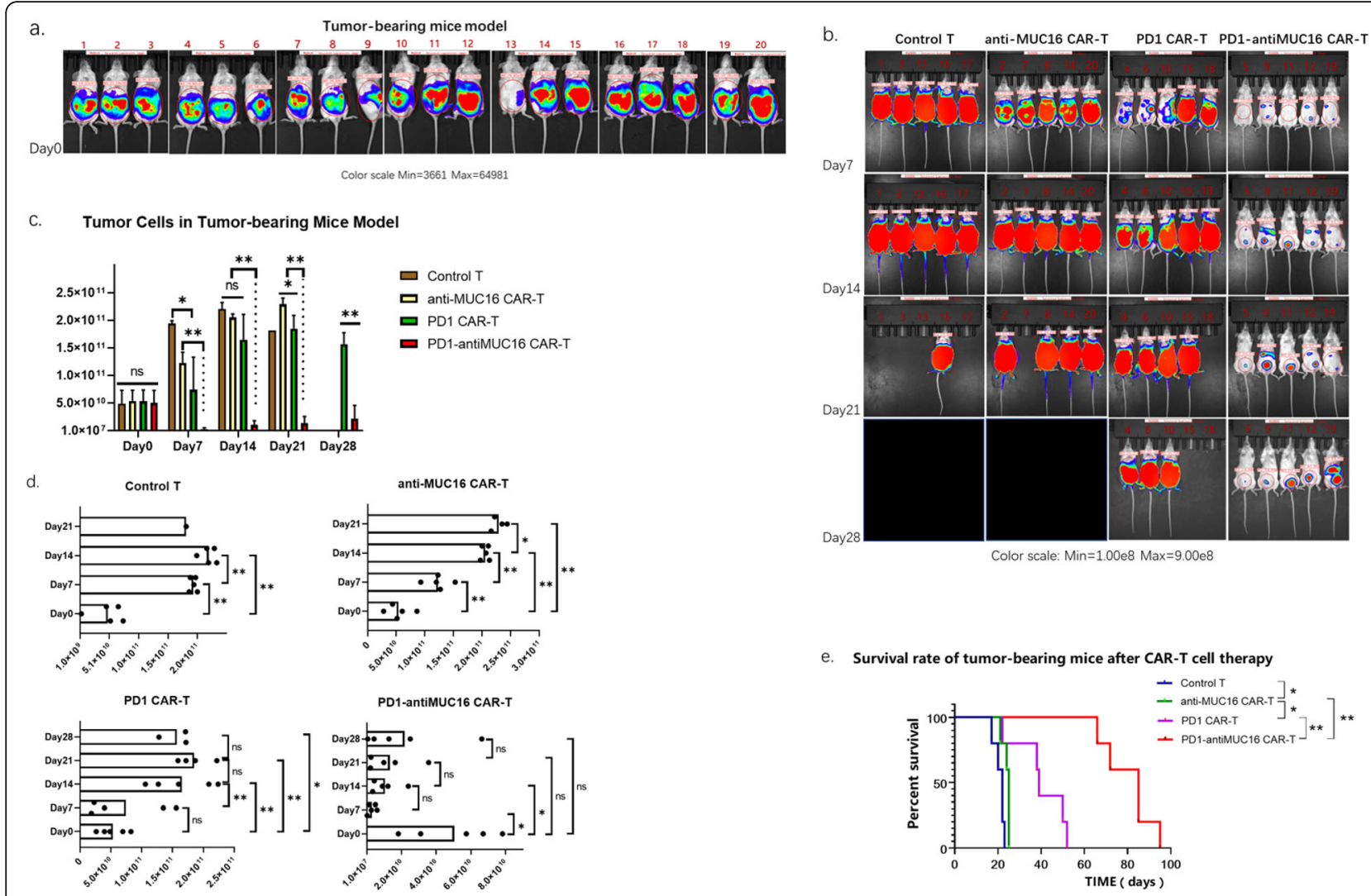

Fig. 7 Therapeutic efficacy of CAR-T cells on the xenograft mice model. a The Vivo imaging results of OVCAR3-MUC16-GFP-PDL1-IUC tumorbearing mice before treatment. NPG mice were intraperitoneally injected with OVCAR3-MUC16-GFP-PDL1-luc cells $\left(5 \times 10^{5}\right)$ and 50 ul Matrigel for $48 \mathrm{~h}$, followed by measuring via IVIS Spectrum and analyzed by Living Image. $\mathbf{b}$ The Vivo imaging results of tumor progression in mice at four points (day 7, day 14, day 21 and day 28) in time, and were randomized divided into four groups. The black area and empty spaces indicate the mice have died. $\mathbf{c}$ The therapeutic effects of the four T cells are compared at the same point in time. $\mathbf{d}$ The therapeutic effect of each $T$ cell group is compared at different points in time. e The survival curve of tumor-bearing mice. All groups below the horizontal line have been compared, the two groups pointed by the arrow line are compared. Data show the mean $\pm S D$, and the results were analyzed with Student't test. Error bars represent the SD. The survival curve was drawn by GraphPad Prism 8.3.0 software. ns: $P>0.05^{*}$ : $P<0.05$, * : $P<0.01$.

T19 had no significant immunotoxicity, including the mean body mass, blood cells counts, and no CRS was observed by detecting IL-10, IL-6, IFN- $\gamma$, and TNF in adult acute lymphoblastic leukemia NSG mice models [38]. However, the study of CAR-T side effects is not involved in this study, which need to be studied by preclinical trials. For future studies of dual CAR-T cells against EOC, we plan to work on topics such as optimal injection dose, treatment cycle, and further preclinical safety evaluation.

\section{Conclusion}

We demonstrated that PD1-antiMUC16 dual-target, and single-target CAR- $\mathrm{T}$ cells possess cytotoxicity against OVCAR-3 cell line expressing PDL1 and MUC16 antigens and induce cytokines release in vitro. Dual CAR-T cells demonstrated advantages of therapeutic effect on OVCAR3-MUC16-GFP-PDL1-luc tumor-bearing mice and significantly prolonged survival time. Single CAR-T cells also inhibited tumor cell proliferation in tumorbearing models and prolonged the survival time. PD1antiMUC16 CAR-T cells demonstrated a therapeutic effect and the experimental data may support further research work that will potentially lead to clinical studies.

\section{Supplementary information}

Supplementary information accompanies this paper at https://doi.org/10. 1186/s12885-020-07180-X.

Additional file 1: Figure S1. Full-length gels of dual-target CAR. a, $1 \mathrm{~KB}$ marker was used as a standard marker. Anti-MUC16 F fragment and antiMUC16 R fragment were utilized for constructing the anti-MUC16 fragment. PD1-M was performed as a mock form of PD1. The left side of the clipping line was Fig. 2. The base length of anti-MUC16 F, anti-MUC16 R, PD1-M, and PD1 was 813 bp,510 bp,700 bp, and 510 bp, respectively. b, All bands were anti-MUC16 fragments and the length about $1500 \mathrm{bp}$. The two bands on the left, more evident than the others, were displayed for subsequent experiments. c, The $8000 \mathrm{bp}$ band and 10,000 bp band in standard bands were not wholly distinguished. Mock marked a 7000 bp band. PLV-PD1-antiMUC16 plasmid consisted of a dual CAR structure with 
a 2000 bp band and a base skeleton with 7435 bp. d, After amplifying in bacterial solution, PD1-antiMUC16 was measured by agarose gel electrophoresis. Mock marked $1500 \mathrm{bp}$ band. All images of gel were performed by DNA sequence analysis of electrophoresis apparatus (LIUYI BIOTECHNOLOGY, Beijing, China).

\section{Abbreviations}

EOC: Epithelial ovarian cancer; OC: Ovarian cancer; CAR-T : Chimeric antigen receptor T; IL-2: Interleukin-2; IFN- $\gamma$ : Interferon- $\gamma$; TNF-a: Tumor necrosis factor-a; CRS: Cytokine release syndrome; MUC16: Mucin 16; PD1: Programmed cell death-1; PDL1: Programmed cell death-ligand 1; CTLA-4: Cytotoxic T lymphocyte-associated antigen-4; UBMC : Umbilical blood mononuclear cell; FBS: Fetal bovine serum; scFv: Single chain antibody fragment; FDA: Food and Drug Administration; PBS: Phosphate buffer saline; PEl: Polyetherimide; GFP: Green fluorescent protein; SPF: Specific pathogenfree

\section{Acknowledgements}

We gratefully acknowledge the technical assistance of Dr. Guoqiu Lu, Xiaojie Cong, Haolan Li, and Dayong Bai. They all worked for Juventas Cell Therapy Ltd. (Tianjin, China).

\section{Authors' contributions}

Conceptualization and statistics by TL; methodology and design of experiment by JDW; Review and editing by JDW and TL; Project Administration by JDW. All authors read and approved the final manuscript.

\section{Funding}

Clinical medicine development special funding of Beijing Municipal Administration of Hospitals (code: XMLX201846). This funding facilitated the collection, analysis, and interpretation of data and in writing the manuscript. The results have applied to the National Intellectual Property Administration, PRC for invention and creation patent, code: 202010066128.3.

\section{Availability of data and materials}

Data supporting the results in the article are available from the corresponding author upon reasonable request.

\section{Ethics approval and consent to participate}

This study was approved by the Medical Ethics Committee, Beijing Obstetrics and Gynecology Hospital, Capital Medical University (2018-KY-026-01), including the cell lines used in the study. Written consent to participate was signed by all healthy donors.

\section{Consent for publication}

Not applicable.

\section{Competing interests}

The authors declare that they have no conflict of interest.

\section{Received: 28 April 2020 Accepted: 13 July 2020}

\section{Published online: 20 July 2020}

\section{References}

1. Siegel RL, Miller KD, Jemal A. Cancer statistics, 2015[J]. CA Cancer J Clin. 2015:65(1):5-29.

2. Jeon SY, Hwang KA, Choi KC. Effect of steroid hormones, estrogen and progesterone, on epithelial mesenchymal transition in ovarian cancer development[J]. J Steroid Biochem Mol Biol. 2016;158:1-8 S0960076016300188.

3. Torre LA, Trabert B, Desantis C, et al. Ovarian cancer statistics, 2018[J]. CA Cancer J Clin. 2018;68(4):284-96.

4. Xu X, Qiu J, Sun Y. The basics of CAR T design and challenges in immunotherapy of solid tumors - ovarian cancer as a model[J]. Hum Vaccin Immunother. 2017:13:1-8.

5. Kruger S, Ilmer M, Kobold S, et al. Advances in cancer immunotherapy 2019 - latest trends[J]. J Exp Clin Cancer Res. 2019;38(1):268.

6. Whilding Lynsey M, Leena H, Benjamin D, Parente-Pereira Ana C, Tomasz Z, Marc DD, John M. CAR T-Cells Targeting the Integrin avB6 and CoExpressing the Chemokine Receptor CXCR2 Demonstrate Enhanced
Homing and Efficacy against Several Solid Malignancies [J]. Cancers. 2019; 11(5):674.

7. Song DG, Ye Q, Santoro S, et al. Chimeric NKG2D CAR-expressing T cellmediated attack of human ovarian Cancer is enhanced by histone Deacetylase inhibition[J]. Hum Gene Ther. 2013;24(3):295-305.

8. Owens GL, Sheard VE, Kalaitsidou M, et al. Preclinical assessment of CAR Tcell therapy targeting the tumor antigen 5T4 in ovarian Cancer[J]. J Immunother. 2018:41:130-40.

9. Schneider D, Xiong Y, Wu D, et al. A tandem CD19/CD20 CAR lentiviral vector drives on-target and off-target antigen modulation in leukemia cell lines[J]. J ImmunoTherapy of Cancer. 2017;5(1):42.

10. Evripidis L, Mathilde P, Klattenhoff Alex W, Degang S, Raphael S, June Carl $\mathrm{H}$, Powell Daniel J. Chimeric antigen receptor T cells with dissociated signaling domains exhibit focused anti-tumor activity with reduced potential for toxicity in vivo. [J]. Cancer Immunol Res. 2014;1(1):43-53.

11. Hegde M, Mukherjee M, Grada Z, et al. Tandem CAR T cells targeting HER2 and IL13Ra2 mitigate tumor antigen escape[J]. J Clin Invest. 2016;126(8): 3036-52.

12. Wilkie S, Schalkwyk MCl, Hobbs S, et al. Dual targeting of ErbB2 and MUC1 in breast Cancer using chimeric antigen receptors engineered to provide complementary signaling [J]. J Clin Immunol. 2012;32(5):1059-70.

13. Felder M, Kapur A, Gonzalez-Bosquet J, et al. MUC16 (CA125): tumor biomarker to cancer therapy, a work in progress[J]. Mol Cancer. 2014;13(1):129.

14. Liu Q, Cheng Z, Luo L, et al. C-terminus of MUC16 activates Wnt signaling pathway through its interaction with $\beta$-catenin to promote tumorigenesis and metastasis [J]. Oncotarget. 2014;7(24):36800-13.

15. Taube JM, Anders RA, Young GD, et al. Colocalization of Inflammatory Response with B7-H1 Expression in Human Melanocytic Lesions Supports an Adaptive Resistance Mechanism of Immune Escape [J]. Sci Transl Med. 2012:4(127):127ra37.

16. Zou W, Chen L. Inhibitory B7-family molecules in the tumour microenvironment[J]. Nat Rev Immunol. 2008:8(6):467-77.

17. Abiko K, Matsumura N, Hamanishi J, et al. IFN- $\gamma$ from lymphocytes induces PD-L1 expression and promotes progression of ovarian cancer[J]. Br J Cancer. 2015;112(9):1501-9.

18. Qu QX, Xie F, Huang Q et al. Membranous and cytoplasmic expression of PD-L1 in ovarian Cancer cells[J]. Cell Physiol Biochem. 2017;43:1893-906.

19. Cherkassky L, Morello A, Villena-Vargas J, et al. Human CAR T cells with cellintrinsic PD-1 checkpoint blockade resist tumor-mediated inhibition [J]. J Clin Invest. 2016;126(8):3130-44. https://doi.org/10.1172/JCl83092 Epub 2016 Jul 25.

20. Fan C, Reader J, Roque DM. Review of Immune Therapies Targeting Ovarian Cancer[J]. Curr Treat Options in Oncol. 2018;19(12):74.

21. Peng W, Liu C, Xu C, et al. PD-1 blockade enhances T-cell migration to tumors by elevating IFN- $\gamma$ inducible chemokines[J]. Cancer Res. 2012;72(20): 5209-18.

22. Strickland KC, Howitt BE, Shukla SA, et al. Association and prognostic significance of BRCA1/2-mutation status with neoantigen load, number of tumor-infiltrating lymphocytes and expression of PD-1/PD-L1 in high grade serous ovarian cancer. [J]. Oncotarget. 2016;7(12):13587-98.

23. Abiko K, Mandai M, Hamanishi J, et al. PD-L1 on tumor cells is induced in ascites and promotes peritoneal dissemination of ovarian cancer through CTL dysfunction. [J]. Clin Cancer Res. 2013:19(6):1363-74.

24. Sui $X, M a J, H a n ~ W$, et al. The anticancer immune response of anti-PD-1/PD$\mathrm{L} 1$ and the genetic determinants of response to anti-PD-1/PD-L1 antibodies in cancer patients[J]. Oncotarget. 2015;6(23):19393-404.

25. Marco R, Barrett DM, Kenderian SS, et al. Dual CD19 and CD123 targeting prevents antigen-loss relapses after CD19-directed immunotherapies[J]. J Clin Investig. 2016;126(10):3814-26.

26. Grosser R, Cherkassky L, Chintala N, et al. Combination immunotherapy with CAR T cells and checkpoint blockade for the treatment of solid tumors[J]. Cancer Cell. 2019:36(5):471-82.

27. Feng $X, X u$ W, Li Z, et al. Disease Immunotherapy: Immunomodulatory Nanosystems (Adv. Sci. 17/2019)[J]. Adv Sci. 2019:6(17):1900101.

28. Liu X, Ranganathan $R$, Jiang $S$, et al. A chimeric switch-receptor targeting PD1 augments the efficacy of second-generation CAR T cells in advanced solid tumors[J]. Cancer Res. 2016;76(6):1578-90.

29. Sanchez E, Smith EJ, Yashar MA, et al. The role of B-cell maturation antigen in the biology and management of, and as a potential therapeutic target in multiple myeloma[J]. Target Oncol. 2018:13(1):39-47 http://kns.cnki.net/ kcms/detail/61.1415.R.20190903.1344.172.html. 
30. Ma F, Jin-Yuan H, Huan D, Fan X, Wu X, Wang Q, Wang L, Ying L, Min B, Wang Y, Luo J, Jianqiang L. Evidence of Long-Lasting Anti-CD19 Activity of Engrafted CD19 Chimeric Antigen Receptor Modified T Cells in A Phase I Study Targeting Pediatrics with Acute Lymphoblastic Leukemia.[J]. Hematol Oncol. 2019;37(5):601-8.

31. Jie L, Zhenyu W, Naiqing Z. Individual Patient Data Meta-Analysis from 16 Trials for Safety Factors in Cytokine Release Syndrome After CAR-T Therapy in Patients with Non-Hodgkin Lymphoma (NHL) and Acute Lymphoblastic Leukemia.[J]. Adv Ther. 2019;36(10):2881-94.

32. Leong L, Tan HL, Cua S, et al. Preclinical Activity of Embryonic Annexin A2Specific Chimeric Antigen Receptor T Cells Against Ovarian Cancer[]]. Int J Mol Sci. 2020;21(2):381.

33. Zhu $X$, Cai $H$, Zhao $L$, et al. CAR-T cell therapy in ovarian cancer: from the bench to the bedside[J]. Oncotarget. 2017;8(38):64607-21.

34. Teachey DT, Lacey SF, Shaw PA, et al. Identification of Predictive Biomarkers for Cytokine Release Syndrome after Chimeric Antigen Receptor T-cell Therapy for Acute Lymphoblastic Leukemia[J]. Cancer Discov. 2016;6(6):664-79.

35. Wang Z, Han W. Biomarkers of cytokine release syndrome and neurotoxicity related to CAR-T cell therapy[]]. Biomarker Res. 2018;6(1):4.

36. Lee DW, Gardner R, Porter DL, Louis CU, Ahmed N, Jensen M, Grupp SA, Mackall CL. Current concepts in the diagnosis and management of cytokine release syndrome. Blood. 2014;124:188-95.

37. Ren J, Zhang X, Liu X, Fang C, Jiang S, June CH, Zhao Y. A versatile system for rapid multiplex genome-edited CAR T cell generation. Oncotarget. 2017; 8:17002-11. https://doi.org/10.18632/oncotarget.15218.

38. Wen $\mathrm{H}, \mathrm{Qu} Z$ Z, Yan Y, et al. Preclinical safety evaluation of chimeric antigen receptor-modified T cells against CD19 in NSG mice[J]. Ann Transl Med. 2019; $7(23): 735$

\section{Publisher's Note}

Springer Nature remains neutral with regard to jurisdictional claims in published maps and institutional affiliations.

Ready to submit your research? Choose BMC and benefit from:

- fast, convenient online submission

- thorough peer review by experienced researchers in your field

- rapid publication on acceptance

- support for research data, including large and complex data types

- gold Open Access which fosters wider collaboration and increased citations

- maximum visibility for your research: over $100 \mathrm{M}$ website views per year

At $\mathrm{BMC}$, research is always in progress.

Learn more biomedcentral.com/submissions 